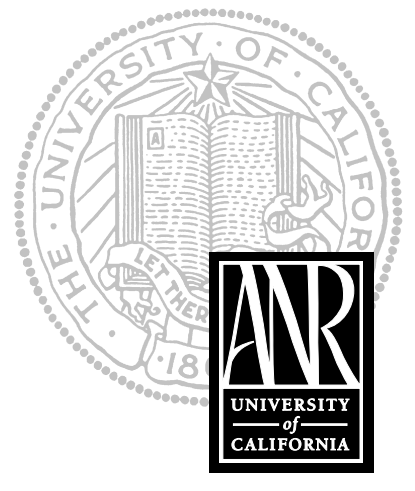

\section{UNIVERSITY OF CALIFORNIA}

Agriculture and Natural Resources

http://anrcatalog.ucdavis.edu

PUBLICATION 8039

\title{
Sago Palms in the Landscape
}

Pamela M. Geisel, University of California Cooperative Extension Farm Advisor, Environmental Horticulture, Fresno County; Carolyn L. Unruh, University of California Cooperative Extension Fresno County staff writer; Patricia M. Lawson, illustrator.

In many landscapes, particularly in the mild-winter regions of California, one plant seems to stand out as a significant specimen or garden focal point: the sago palm (Cycas revoluta). As plants go, sagos have charisma. They possess a noble character and add an exotic touch to any landscape. Yet in addition to inspiring landscape designers, they can also inspire larceny!

Sagos are not particularly difficult to grow, but their very slow growth rate-usually only one flush of new growth per year-makes large specimens quite valuable. As a result, homeowners are often forced to take precautions to prevent their prized sagos from disappearing in the night. One method to deter theft consists of pounding 3-foot (1-m) lengths of rebar into the soil around the trunk about 2 inches (5 $\mathrm{cm}$ ) apart. The tops of the rebar strips should be at or just below the soil line. In time, the roots of the sago will entwine themselves in the rebar, making the plant much more difficult to remove. Concrete collars, chains and padlocks, and spotlights have also been used to discourage theft.

Interestingly, sagos are not really palms, although their appearance resembles that of true palm trees. They are cycads and have an unusual reproductive process that places them, phylogenically speaking, somewhere between flowering plants and ferns. Like pines and other conifers, Gingko spp., and Podocarpus spp., sagos are gymnosperms, which reproduce by means of wind- and insect-carried male spores that land on the female "inflorescence."

Cycads are dioecious, meaning that there are separate male and female plants. Plants of both sexes must be within fairly close proximity in order to produce seed. During pollination, spermatozoids produced by the male plant fertilize the ovules of the female plant. The male "flowers" (microsporophylls) develop on a large upright cone in the center of the plant (fig. 1), while the female "flowers" (megasporophylls) are generally lower, forming a round, somewhat flattened globe also in the center of the plant (fig. 2).

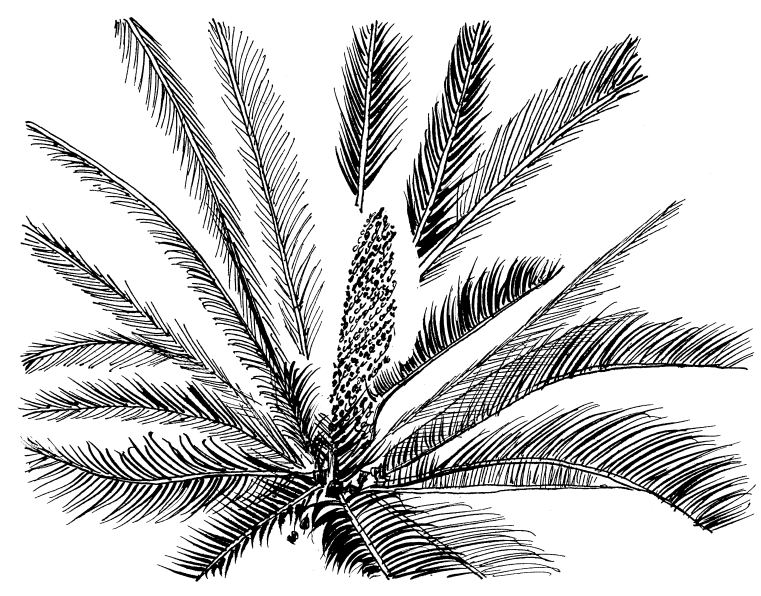

Figure 1. The male "flowers" (microsporophylls) of the sago develop on a large, upright cone in the center of the plant.

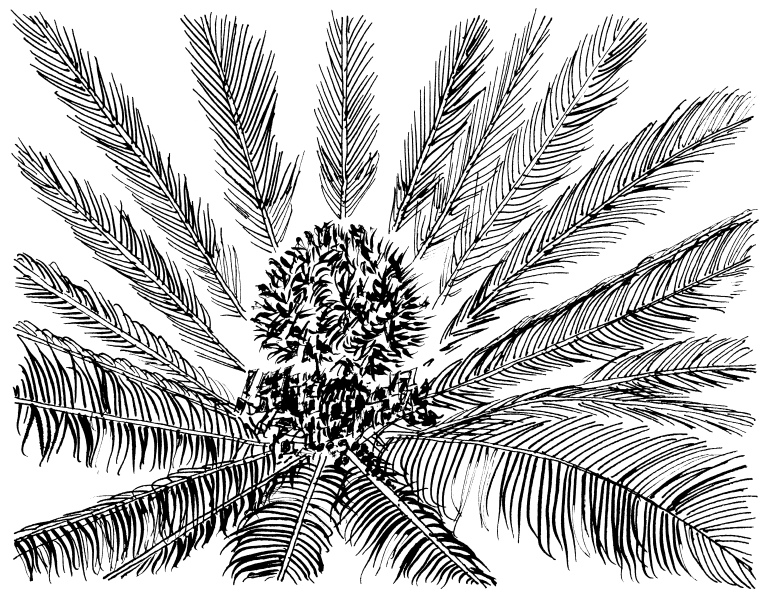

Figure 2. The female "flowers" (megasporophylls) of the sago form a round, somewhat flattened globe in the center of the plant. 
Some people consider the cones unattractive; they can be carefully removed at any time without affecting the plant's growth or health. In most cases, however, it is best to leave them in place and let them break apart naturally. This will avoid accidentally damaging the growing point in the center of the plant, through which a flush of new leaves will eventually emerge.

Late in the year, usually around December, bright red seed develop on the female cone if it has been pollinated. The seed keep well for about a month or more after ripening. To propagate the plant, sow the seed in shallow boxes, setting them on the surface of clean sand. Keep the soil moist (not soggy) and warm $-80^{\circ}$ to $85^{\circ} \mathrm{F}$ (about $26^{\circ}$ to $30^{\circ} \mathrm{C}$ ) is optimal. After germination, transplant the seedlings to small containers and keep them in partial shade.

Sagos can also be propagated from the offsets, or "pups," that arise from around the base of the plant. The best time to remove the pups is in the spring just before warm weather begins. The pups will have few roots, or none at all, so most of the fronds should be removed to reduce water loss. Before planting, let the pups air-dry in the shade for a few days so the moist wound and/or cut roots can heal over or form a callus. Then plant them in small containers filled with a fast-draining medium such as sand or perlite. To minimize the occurrence of stem or root rot, the potting mixture should be just slightly moist. Keep the plants in filtered light or under shade cloth until well rooted, a process that may take several weeks or even months.

Sagos are relatively easy to grow once they are planted in the landscape, and they have very few pest problems. They are susceptible to stem rots under conditions of excessive irrigation and poor drainage and aeration. Scale insects and mealybugs can sometimes be a serious problem. Sagos also succumb to sunburn under high temperatures and intense light conditions. While sagos will tolerate full sun, they look better when grown in partial shade. Too much sunlight may cause the leaves to turn yellow, especially in inland areas.

Sagos are among the hardiest cycads, reportedly tolerating temperatures as low as $15^{\circ} \mathrm{F}$ (about $-10^{\circ} \mathrm{C}$ ). However, below $23^{\circ} \mathrm{F}$ (about $-5^{\circ} \mathrm{C}$ ) most will sustain some damage to foliage, which may show up later as black leaf spots. If severe winter weather is anticipated, move container-grown plants inside or under overhanging eaves. Protect the crowns of landscape sagos by covering them with frost blankets.

Sagos planted in good garden soil do not require much fertilizer. They have only one or two flushes of growth per year, so heavy nitrogen applications are not needed. Generally, the best results can be obtained with the use of slow-release fertilizers or products like blood meal or bone meal, which decompose slowly and provide a constant supply of nutrients. Sagos should do well with a formulation high in potassium $(\mathrm{K})$ and magnesium $(\mathrm{Mg})$. Deficiency of these two elements appears as orange flecking or yellowing on the lower leaves. Sagos also seem to benefit from the application of chelated iron and trace minerals when they show signs of yellowing (chlorosis) that cannot be attributed to sunburn. Although yellowing of the mature foliage will not be corrected by an application of micronutrients, the next flush of new growth should exhibit a greener, healthier color. 


\section{FOR MORE INFORMATION}

Wrinkle, G. 1995. Cycads: Their cultivation and propagation. Golden Boy Press.

Visit our online catalog at http://anrcatalog.ucdavis.edu. You can also place orders by mail, phone, or fax, or request a printed catalog of publications, slide sets, and videos from

University of California

Agriculture and Natural Resources

Communication Services

6701 San Pablo Avenue, 2nd Floor

Oakland, CA 94608-1239

Telephone: (800) 994-8849 or (510) 642-2431, FAX: (510) 643-5470

E-mail inquiries: danrcs@ucdavis.edu

An electronic version of this publication is available on the ANR Communication Services website at http://anrcatalog.ucdavis.edu.

\section{Publication 8039}

Funding for this publication was made possible through a grant from the Elvenia J. Slosson Fund.

(C)2001 by the Regents of the University of California, Division of Agriculture and Natural Resources. All rights reserved.

The University of California prohibits discrimination against or harassment of any person employed by or seeking employment with the University on the basis of race, color, national origin, religion, sex, physical or mental disability, medical condition (cancer-related or genetic characteristics), ancestry, marital status, age, sexual orientation, citizenship, or status as a covered veteran (special disabled veteran, Vietnam-era veteran or any other veteran who served on active duty during a war or in a campaign or expedition for which a campaign badge has been authorized). University Policy is intended to be consistent with the provisions of applicable State and Federal laws.

Inquiries regarding the University's nondiscrimination policies may be directed to the Affirmative Action/Staff Personnel Services Director, University of California, Agriculture and Natural Resources, 300 Lakeside Drive, 6th floor, Oakland, CA 94612-3550; (510) 987-0096. For a free catalog of other publications, telephone (800) 994-8849. For help downloading this publication call (530) 754-5112.

pr-10/01-SB/VFG

ISBN 978-1-60107-217-7

This publication has been anonymously peer reviewed for technical accuracy by University of California scientists and other qualified professionals. This review process was managed by the ANR Associate Editor for Environmental Horticulture. 